\title{
Is Steering Humanity A Good Idea?
}

\author{
Armin Nikkhah Shirazi
}

University of Michigan, Ann Arbor

\begin{abstract}
The notion that humanity should steer the future may seem inviting at first, but this paper points out two problems with it. First, it is argued that a society with the kind of features most people would find desirable and would want to "steer" to can only be realized if most of its members share a set of suitable universal values and take these as guidelines for living. Examples of rules that reflect these values are given. Second, it is pointed out that there is a small minority of the population that suffers from certain psychopathological disorders which may help some of its members to rise to the top of society and initiate efforts to "steer" humanity for their own ulterior motives. Starting with Political Ponerology, the work of Andrew Lobaczewski, a mechanism is proposed which describes the process by which the members of that minority rise to the top. The mechanism is called pathoselection. Some indirect evidence is presented that such a mechanisms may already be at work in the United States, though its testability is inherently limited as it requires the psychological testing of individuals at the top of society.
\end{abstract}

\section{Introduction}

If one attempts a cursory assessment of the current state of the world, one finds both reason for hope and grounds for despair. On the one hand, in parts of the world people enjoy unprecedented prosperity, freedom, and opportunities for self-actualization. Our knowledge is increasing exponentially, technological innovations continually transform our lives and in parts of the world some of us have not needed to fear the prospects of war and famine for a long time. People in many other parts of the world, on the other hand, are not so fortunate. In many places they starve, lack access to clean water and other basic necessities, and live in constant fear of violence, disease, political instability and other calamities. Aside from these problems, the world as a whole faces threats associated with climate change, the exhaustion of natural resources, and the proliferation of weapons of mass destruction.

In light of these challenges it is tempting to ask how humanity should steer the future, where the notion of "steering" seems to imply a form of direction by a small and presumably enlightened group which has the best interests of humanity at heart, the best knowledge of how to further these interests and the means to do so.

The central thesis of this paper questions the premise that such steering is desirable. Rather, if every citizen were instilled with certain foundational values from childhood on which are integrated as guidelines for living, then the individual actions of each in accordance with these values may cascade upward so that the aggregate manifests itself eventually at a societal level. In that case, societal actions would already reflect the best interests of humanity as a whole, rendering the need for any kind of "steering" unnecessary. Moreover, there is a small minority of the population that suffers from one or more kinds of psychopathological disorders which may help at least some of its members to rise to the top societal strata. Active "steering" by such individuals, when they are in positions of power, is to be strongly opposed, and many efforts at "steering" humanity, however ostensibly benign, may in fact be initiated by such individuals for their own ulterior motives.

\section{The Prosperous Society}

Let us first articulate a vision for a type of society that is not in need of any "steering" of the kind mentioned above. We will call this idealization the Prosperous Society, by which we mean not just that it has great material wealth, although that may certainly also be the case. Rather, a prosperous society begins at bottom by being one in which none of its members faces a preventable existential threat such as starvation and death or disability by treatable illness or crime. Additionally, mechanisms exist to help protect individuals from the consequences of catastrophic events.

In a Prosperous Society, the governance reflects the will of the majority by vote, though the needs of the minority are accommodated as much as possible and whenever they do not impinge on the majority's needs. Members of this society have several (meaning more than two) real options of political persuasions to choose from, and the options 
are in fact substantially distinct from each other. Freedom of expression is not just professed but instantiated every time an individual voices highly unpopular views without the fear of negative consequences. Freedom from discrimination or persecution based on age, race, religion, gender, sexual or political orientation and physical disability is guaranteed.

In a Prosperous Society, there is a strict separation of religion, money and politics or, more emblematically, of church, corp and state. For example, the amount of political advertising allotted to each political candidate in the media is strictly limited, but available free of charge, and religious organizations and business entities are barred from contributing financially to or even endorsing in an official capacity particular political candidates. Voters may contribute up to a nominal amount, but support in the form of volunteer work is more highly encouraged. The religious beliefs of each political candidate are treated largely as a private matter.

Members of this society are free from the intrusion on privacy by the government or other organizations, and almost all political organizations are completely transparent. Both illegal and legalized corruption is low or non-existent, as are crime rates in general, and for all but the most recidivist or violent criminals, rehabilitation is given a higher priority than incarceration. Education is a high priority in this society and is not limited to the mere acquisition of knowledge, but geared towards developing a whole individual and a productive member of society.

Institutions function properly and reliably, but more importantly, people can rely on each other. Interpersonal trust in this society is very high. Virtually every member is afforded an opportunity to actualize his or her dreams, and to the extent that such actualization benefits society as a whole, there exist mechanisms to give it full support. On the other hand, the rise of powerful special interest groups which attempt to benefit themselves at the expense of the rest of society is undercut by a vigilant observation and exposition of their practices. Income disparities exist, but they are "healthy" in the sense that they largely reflect how much money people wish to earn relative to how much they wish to allot their time and resources to the pursuit of interests which do not result in earned income. In other words, it is largely a disparity by choice.

The foreign policy of the governance is marked by enlightened self-interest and a long-term perspective, looking for win-win solutions with other societies that observe minimum ethical standards and a clear view of how present-day choices will affect future generations. Its domestic policy is shaped by concern for ensuring the existence of an infrastructure that fosters the realization of the full potential of each member while protecting members from the consequences of realized potentials that could lead to harm to others. Economic, social and political problems are addressed right away and not tabled for later. Scientific methods are employed to help find solutions to these problems.

The Prosperous Society sees itself as a steward of nature. The conservation of its natural resources is a high priority and basic science research as well as applied research, particularly in the field of alternative Energy sources, is supported in concrete ways. Investments in the well being and education of members of the society high priorities, while investment in the military is primarily for defensive purposes. Safeguards exist to prevent the emergence of a shadowy military-industrial complex.

The above describes something that comes close to the ideal society in this author's mind, but there is no doubt that any other person's vision of a prosperous society will be different, and sometimes very much so. Nonetheless, it is probably fair to assume that certain features will be common to most people's notions of a prosperous society, such as protection from existential threats, high levels of trust, low levels of crime, individual freedoms of various kinds, and opportunities for self-actualization.

\section{Some Foundational rules for a Prosperous Society}

A prosperous society does not simply materialize on its own, nor can a society be "steered" into becoming prosperous. Rather, if not everyone, then certainly a large portion of its members must contribute at least something 
to its genesis by being responsible, proactive, productive and ethical citizens. This depends heavily on them having a system of shared universal values which is conducive to the creation of such a society. These values can be translated into rules used to guide the actions of individuals. One could talk about these rules in generalities, but in order to flesh out the thesis more concretely, we will give some examples below. No claim is made that the following list is exhaustive. Also, these are not to be taken as "carved in stone", in the sense that a particular set of values may be expressed in terms of many different sets of rules. However, it is still the case that in order to give rise to a prosperous society the different sets of rules must reflect a shared set of values. Finally, it is likely that almost everybody already "knows" these rules at least at some level, but there is a huge difference between a vague awareness of a rule and structuring one's life in accordance with it.

- Treat others as you would like to be treated. It is for good reason that the golden rule has been around for thousands of years. Many other values, such as empathy for others, mutual respect, fairness and so on, which are highly conducive of a prosperous society, derive from it. Of course, if you would like to be treated in a particularly unusual way, it may not be a good idea to treat others likewise. The application of the golden rule, like that of all the other rules presented below, requires the use of a modicum of judgment.

- Doubt everything at least a little. The blind adherence to dogma may well be one of the main inhibitors of the progress of humanity and a chief source of human-caused suffering. Thus, if one can distinguish what one wishes to be true from what is actually true then it will often not only benefit oneself but also others. This distinction lies at the heart of our most successful system of methods of learning objective facts, namely science. Ironically, often those who are most trained in making this distinction are far underrepresented among those in political power, while those who are most trained to convince others of the truth of an argument regardless of whether it is actually true or not, such as lawyers, are vastly overrepresented.

- Own your share of responsibility for everything that happens to you. It is probably the case that if asked, virtually everyone would claim to take responsibility for their share of what happens to them. But people's actions often tell a different story. For example, it is extremely common for Americans to complain about and disapprove the work of Congress. The complaints may well be justified, but if we live in a functioning democracy, then the people who are in Congress represent us, and therefore, their failure is our failure. At the very least, it is our failure to replace them with a better alternative. Yet, in many cases, year after year incumbents are re-elected and people continue with their gripes.

- Do the right thing because it is the right thing to do. This substantially deviates from the message of Western religions, according to which the reward for good and bad deeds, however defined, is an afterlife in heaven and hell, respectively. To this author, at least, this amounts to a grand cosmic bribery and extortion scheme. The recognition that doing the right thing is its own reward is part of what makes us human. When it comes to right and wrong, carrots and sticks are for the animals.

- If an authority strikes you as genuinely unjust, consider disobedience. The operative keyword here is "consider". What one should actually do depends on factors such as one's confidence in having access to all the facts, the degree of injustice, the availability of alternative mechanisms to correct the injustice, the particular disobedient action and its consequences. Again, like all these kinds of rules, the application of this rule requires a modicum of judgment

It may be charged that instilling values by means of such rules in children is a form of indoctrination. That is correct, but it is hard to imagine that children could grow up without ever being exposed to some indoctrinating influences from somewhere. Even if parents refrain from inculcating any values at all in their child, its peers, schools, other adults, media role models, advertisers and marketers certainly will not and at least some of the values acquired in this way may actually be harmful to that person. Therefore, if there ever was any situation in which indoctrination was a good thing, this would have to be it. 
To summarize, the argument is that if a large number of people were instilled with a suitable shared value system, as partially represented by the rules above, which they implemented as guidelines for living, then they could form a Prosperous Society, which has no need for "steering" because the impetus for advancing the interests of humanity essentially comes from the aggregate of the actions of each or at least most of its members.

Unfortunately, the picture painted above may seem far too utopian and unrealistic for most people, their views undoubtedly tempered by the fact that such Prosperous Societies have probably never existed, at least at a large scale. Instead, what marks historical events far more often is tyranny, bloodshed, corruption, warfare, power struggles, famine, natural catastrophes and so on. It is perhaps not too much of an exaggeration to say that history is for the most part one long tapestry of human suffering.

Much of human suffering has ultimately been intentionally inflicted by man unto himself, and it is all too easy to shrug this off as a shortcoming in our nature. But doing so essentially abdicates the responsibility for learning from our past to improve our future. The by far best and most reliable methods we have found to help us understand our world better are the methods of science. Thus we should ask whether it is possible to examine the root causes of the historical fact that over and over man keeps on inflicting suffering unto himself as a scientific problem, and it turns out some fledgling efforts toward doing just that have already been made.

\section{Political Ponerology}

During the years following World War II, the Polish Psychologist Andrew Lobaczewski embarked on a long and extraordinarily arduous study of what he would later call Ponerology, derived from the Greek name for evil, poneros. Beginning with the study the nature of totalitarianism, which under the occupation of Poland by the Soviet Union carried great personal risks for him, he was led together to investigate, with other underground researchers, various psychopathologies which impact the political and social course of entire societies (Koehli, 2010). He eventually published a book called Political Ponerology a basic finding of which was that "essential psychopathy is an indispensable requirement for large-scale evil." (Lobaczewski, 2006)

The public perception of the term "psychopath" is heavily distorted because both in movies and in the news the term appears frequently as a description of serial killers. However, it is not a desire to kill people that characterizes most psychopaths but the absence of a conscience, together with diminished ability to experience certain emotions, like love and fear and especially empathy, as well as impulsive behavior. Psychopathy is considered to occur in around $4 \%$ of the population and may have both genetic and environmental causes. The Diagnostic and Statistics Manual of Mental Disorders, $5^{\text {th }}$ ed. (DSM 5), which is sometimes called the 'bible' of mental health professionals, says that psychopathy and sociopathy are different names for antisocial personality disorder (ASPD), but in a section on emerging models also considers psychopathy a "specifier" for ASPD marked by a "bold interpersonal style" (American Psychiatric Association, 2013). Some researchers on psychopathy consider it to be a separate disorder from ASPD. (O'Hare R. , 1996)

According to Hervey Cleckley who pioneered the study of this field, psychopaths can be described as

"Likeable", "Charming", "Intelligent", “Alert", "Impressive", “Confidence-inspiring," and "A great success with the ladies". "[A psychopath's] smooth self-assurance acts as an almost supernatural magnet to normal people who have to read self-help books or go to counseling to be able to interact with others in an untroubled way. The psychopath, on the contrary, never has any neuroses, no self-doubts, never experiences angst, and is what 'normal' people seek to be." (Cleckley, 1941)

While according to Robert O'Hare, another leading researcher on psychopathy,

“... many psychopaths ....appear to function reasonably well — as lawyers, doctors, psychiatrists, academics, mercenaries, police officers, cult leaders, military personnel, businesspeople, writers, artists, entertainers, and so 
forth—without breaking the law, or at least without being caught and convicted." (O'Hare, Without Conscience: The Disturbing world of Psychopaths Among Us, 1993)

According to Martha Stout, who has worked extensively with their victims, psychopaths desire many of the things that most people do, such as money, power, wealth, but their range of means to fulfill their desires is wider because it includes actions most people would feel too inhibited to carry out. The wider range of actions available to them, particularly when coupled with their attractive personas, gives them power, often at the price of inflicting suffering on others. (Stout, 2005)

According to Lobaczewski, societies alternate between "good times" and "bad times" in what he calls the hysteroidal cycle. At the beginning of the process, which he calls Ponerogenesis, a society is not sufficiently guarded against the psychopathic minority, permitting it to gradually infiltrate institutions and the state. Then, by disseminating paralogic and paramoralism (i.e. false logic and moralism) and other measures to mislead society at large, it lays the groundwork for essential psychopaths to take control over the society, turning it into what he calls a pathocracy. The pathocracy, however, is foredoomed because the vast majority of members of society eventually recognize the nature of the pathocrats, resist and eventually overcome them. The fall of the pathocracy heralds the beginning of the "good times", during which people "progressively lose sight of the need for profound reflection, introspection, knowledge of others, and an understanding of life's complicated laws", rendering them once more susceptible to the influences of the psychopathic minority, and starting the hysteroidal cycle once more (Lobaczewski, 2006)

Were Lobaczewski's work better known it would probably be highly controversial. Despite the fact that there is not enough data to verify the empirical basis of his theory (it was destroyed) Lobaczewski's great contribution is that he took a subject within the purview of theology and philosophy and opened the way to consider it a proper subject for science and medicine, leading to the re-interpretation of large-scale evil in history as large-scale manifestations of disease. There is no doubt that Lobaczewski's work can only be considered a beginning and that much more research needs to be done in this area. In particular, he does not seem, to this author at least, to adequately address the profound inherent conflict between the recognition of a dehumanizing illness in a member of society and an ethical obligation on all of us not to dehumanize fellow members of our society, a problem to which this author also lacks a good answer.

\section{Pathoselection and its effect on Society}

Once one becomes aware of ponerogenesis, one may be inclined to ascribe it to conspiracies between psychopaths at the top of society. While in some cases this may be true, this author will present a hypothesis perhaps more amenable to scientific investigation and which is somewhat reminiscent of natural selection. We will call this mechanism pathoselection. We presume that pathoselection can be differentiated into two kinds: Biological and social.

Biological pathoselection refers to the situation in which a person with a psychopathology that has a hereditary component reaches upper societal strata and then passes on some of the same traits to his off-spring, which in turn uses these traits to maintain its social status or reach an even higher one, thereby ensuring an equal or greater chance of success of its off-spring. Biological pathoselection may possibly underlie the development of some economically or politically powerful clans and dynasties.

Social pathoselection refers to the situation in which an individual with a psychopathology rises to the top and restructures aspects of society so that other individuals, not necessarily genetically related to him but sharing similar psychopathological traits, have an advantage in social advance than individuals who do not share these traits. The creation of such conditions may be either intentional or unintentional, and occur over timeframes much shorter than those associated with biological pathoselection. 
Intentional social pathoselection refers to the situation in which a psychopath at the top actively supports the rise of other psychopaths into positions of power and influence based on their psychopathological traits. The classic scenario is that of an immoral chief executive or a military general who promotes other psychopaths to his executive team so that when he needs them to do something unethical or illegal, they are far more likely to carry out his orders than individuals with a conscience. Intentional social pathoselection may lie at the heart of many conspiracies, collusions and instances of nepotism, and may be particularly prevalent in organized crime: Before being permitted to rise to the top of a criminal organization, an individual may need to carry out an especially heinous act to "prove" that he has what it takes to lead the organization.

Unintentional social pathoselection refers to the situation in which a psychopath, in the course of restructuring aspects of society for his own benefit, inadvertently helps other psychopaths gain an advantage in their social advance over normal people by virtue of their psychopathological traits. The classic scenario is that of a psychopathic dictator who inadvertently helps the social advance of psychopaths in his police or military force because they stand out favorably in the ruthlessness by which they execute evil measures mandated by him. A more modern example is that of an ultra-rich psychopath who actively finances political changes harmful to most of society solely because they benefit him but which turn out to benefit other rich psychopaths as well.

A model by which pathoselection may eventually lead to political instability is as follows:

If pathoselection is successful, then over time the proportion of psychopaths to normal people in the top layers of society increases to above its proportion relative to that in the general population. This, in turn, may lead to a positive feedback loop, as, everything else being equal, a greater proportion of psychopaths at the top implies the availability of more resources that can be employed to further their own benefit in unethical and ruthless ways, which may result in further social pathoselection. The positive feedback loop may then lead to an acceleration of the displacement of non-psychopaths from the top as well as an acceleration in the social changes beneficial to the top and harmful to society as a whole. Once a sufficient amount of money, power and influence becomes concentrated in the psychopathic portion of the top stratum, the society becomes a pathocracy. The pathocrats may attempt to distract society at large from the sufferings they inflict by means of distractions like vacuous or escapist forms of entertainment, misinformation disseminated through propaganda machines masquerading as news organizations, or external events like wars, which are invariably portrayed as being necessary and just. In the most extreme cases, pathocrats may attempt to control the masses by sheer force and ruthless suppression of any opposition. As the process continues, the economic, political and social disparities become sufficiently large and prevalent that they cause widespread suffering. It may become transparent to increasing portions of society that actions from the top are largely responsible for its plight, and the urge to do something about the current state of affairs may increase in an ever larger fraction of the population. If a certain critical mass feels sufficiently disenfranchised by these developments and determined to change things regardless of the costs to it, political instability ensues and, if left unaddressed by the pathocrats, may eventually lead to a restructuring of the social order. Sometimes the change may be catalyzed by external forces, as happened to the Nazi Regime and, more recently, some Middle Eastern Dictatorships. At other times, society never reaches such stages because of the utter completeness in which the pathocracy robs the general populace of the ability and will to mount any resistance, as seems to be currently happening in North Korea.

\section{Conclusion: Why Steering Humanity May be a Bad Idea}

The above model can only be considered an initial attempt at a rough description that may be refined, extended into a quantitative model, or falsified with more information and data. The central problem in testing it is that psychopathological disorders must be diagnosed by competent professionals, and people in positions of power are highly unlikely to submit themselves to psychological testing for this purpose. We may therefore never be certain that it describes reality at least in some approximation, but we can also never completely rule it out. Thus, there is always a danger that whatever "steering" is initiated will actually be a ploy to benefit the few at the expense of the 
many, especially since "steering" implies to some extent abdication of responsibility for change at an individual level. The danger is increased in light of evidence that a society is, or is in the process of becoming, a pathocracy. Apart from the fact that conditions imposed on persons seeking financial and political power in the US seem to select for people with psychopathological traits (e.g. they favor those with the ability to express with utter conviction what is expedient at the moment), there is indirect evidence that such a process is in fact happening now:

- George W. Bush's administration led an unprovoked attack against Iraq under the pretense that Saddam harbored weapons of mass destruction. The ensuing conflict has up to now cost thousands of American lives and led to the deaths of over a hundred thousand Iraqis. The reason given by that administration to justify this war turned out to be false, but none of its members, with the exception of Colin Powell (Weisman, 2005), has ever publicly expressed regret over this.

- Barack Obama rose to the top because he convinced many voters that he was an agent of change. As his second term nears completion, it is evident that many of the policies that he had vowed to change are still in place and sometimes even expanded (Kuhnhenn, 2013). More disturbingly, during his administration the nationwide spying on Americans by the National Security Agency reached unprecedented levels, as was unveiled in a leak by Edwards Snowden shortly after NSA director James Clapper assured Congress under oath that it was "not wittingly" spying on Millions or hundreds of millions of Americans (Greenberg, 2013). Obama quickly expressed "full confidence" in Clapper, while Snowden is sought for espionage (Dozier, 2013).

- Recent Supreme Court decisions seem to be designed to facilitate the concentration of the power and influence at the top. For example, a study has found that the current court is by far the most businessfriendly since at least World War (Epstein, Landes, \& Posner, 2013); it has ruled that corporations can spend freely to support candidates for elections, shielded big business from class action antitrust lawsuits, and most recently lifted ceilings on individual campaign donations in individual election cycles (Mears \& Tom, 2014; Mears \& Tom, 2014; Mears \& Tom, 2014; Dozier, 2013). The two justices most proactive in these areas are also the two most recent additions: Samuel Alito and John Roberts (Liptak, 2013).

- There seem to be more blatant instances of what might be called the exceptionalism of the elite. For example, CEO's who get fired routinely leave with multimillion dollar "parachutes" (Green, 2013), ultrarich convicted pederasts escape prison sentences(Conlon \& Stephanie, 2014), corporations with over a billion dollars in profit pay no taxes (Wood, 2013), and so on.

- Since 1980, an increasing share of the wealth and income is shared by the wealthiest households. For instance, a report by the Center on Budget and Policy Priorities shows, while the top 1\% of Americans have had a 38.3\% share of the total income household groups, the bottom 90 percent had a 36.9\% (Stone, Trisi, Sherman, \& Chen, 2014). Furthermore, "the fingerprints of intentional policy decisions are all over this upward redistribution" (Mishel, Bivens, Gould, \& Shierholz, 2012)

For most people, 30 years and more is probably too long a period of time to materially notice the transmutation of a society into a pathocracy. Some of the things you can do to help counteract the these developments are: pledge to vote for a party other than the two major ones; inform yourself more about these issues, educate others about them and support scientific research into them; inculcate your children with values that foster a prosperous society; support the separation of corporation and state.

The one thing you may not wish to support, however, is the "steering" of humanity by an elite few. 


\section{Bibliography}

American Psychiatric Association. (2013). Diagnostic and Statistical Manual of Mental Disorders (Fifth ed.).

Arlington, VA.

Cleckley, H. (1941). The Mask of Sanity. August, GA: C.V. Mosby.

Conlon, K., \& Stephanie, G. (2014, 04 02). CNN. Retrieved from Cable News Network:

www.cnn.com/2014/04/02/justice/delaware-du-pont-rape-case/

Dozier, K. (2013, 07 12). Clapper Unscathed After "Erroneous" Remarks. Real Clear Politics .

Epstein, L., Landes, W., \& Posner, R. (2013). How Business Fares in the Supreme Court. Minnesota Law Review , 97, 1431-1472.

Green, J. (2013, 06 06). Golden Parachutes of \$100 Million for Fired CEO's Outlive Outrage. Bloomberg News .

Greenberg, A. (2013, 06 06). Watch Top U.S. Intelligence Officials Repeatedly Deny NSA Spying on Americans Over The Last Year. Forbes.

Koehli, H. (2010, 02 15). Ponerology 101: Lobaczewski and the origins of Political Ponerology. Retrieved 18 2018, 04, from sott.net: sott.net/article/203026-Lobaczewski-and-the-origins-of-Political-Ponerology

Kuhnhenn, J. (2013, 04 24). Obama Continues Some George Bush Policies Despite Differences in Ideology,

Temperament. Retrieved 04 18, 2014, from Huffington Post: www.huffingtonpost.com/2013/04/24/obama-georgebush-n-3145804.html

Liptak, A. (2013, 05 05). Corporations Find a Friend in the Supreme Court. New York Times .

Lobaczewski, A. (2006). Political Ponerology. New York, NY: Red Pill Press.

Mears, B., \& Tom, C. (2014, 04 02). Supreme Court allows more private money in election campaigns. Retrieved 04 18, 2014, from CNN: www.cnn.com/2014/04/02/politics/scotus-political-donor-limits/

Mishel, L., Bivens, J., Gould, E., \& Shierholz, H. (2012, 09). The State of Working America, 12th edition. Retrieved 04 18, 2014, from epi.org: www.epi.org/multimedia/press-call-release-state-working-america/

O'Hare, R. (1996, 02 01). Psychopathy and Antisocial Personality Disorder: A Case of Diagnostic Confusion.

Psychiatric Times .

O'Hare, R. (1993). Without Conscience: The Disturbing world of Psychopaths Among Us. New York, NU: Guilford Press.

Stone, C., Trisi, D., Sherman, A., \& Chen, W. (2014, 04 17). A Guide to Statistics on Historical Trends in Income

Equality. Retrieved 04 18, 2014, from Centeron Budget and Policy Priorities:

www.cbpp.org/cms/index.cfm?fa=view\&id=3629

Stout, M. (2005). The Sociopath Next Door. New York, NY: Broadway books.

Weisman, S. (2005, 09 09). Powell Calls His U.N. Speech a Lasting Blot on His Record. New York Times . 
Wood, R. (2013, 02 19). Tax Increases? Why Facebook's Billion Dollar Income Isn't Taxed (At All) By IRS. Forbes 